\title{
O diálogo entre saúde e política externa brasileira nos governos de Fernando Henrique Cardoso (1995-2002) e Luiz Inácio Lula da Silva (2003-2010)
}

\author{
The dialogue between health and the \\ brazilian foreign policy in the governments \\ of Fernando Henrique Cardoso (1995-2002) \\ and Luiz Inácio Lula da Silva (2003-2010)
}

DOI: $10.21530 /$ ci.v12n3.2017.630

Tayná Marques Torres Barboza ${ }^{1}$

Leticia Pinheiro ${ }^{2}$

Fernando Pires-Alves ${ }^{3}$

\section{Resumo}

O presente artigo busca verificar a instrumentalidade do tema da saúde para a participação ativa e propositiva do Brasil na política internacional entre 1995 e 2010. O tema provocava discussões complexas, constantes e marcantes em diversos fóruns globais nesse período, quando os governos de Fernando Henrique Cardoso e Luiz Inácio Lula da Silva buscavam uma atuação internacional relevante e influente. Seus governos divergiam sobre as responsabilidades e oportunidades do Brasil no sistema internacional, mas compartilhavam o objetivo de assumir posição de influência na política internacional. Na busca estratégica por credibilidade, no período FHC, e por autonomia, no período Lula da Silva, o país assumia uma espécie de dever global, que seria realizado por meio de diversas parcerias internacionais e pela participação em instituições globais de relevo. Nesse esforço, parecia necessário formalizar o tratamento do tema da saúde na agenda da política externa brasileira, o que ocorreria em um processo de institucionalização que implicou, entre 1995 e 2010, a adoção

1 Escola Nacional de Saúde Pública Sergio Arouca (ENSP) da Fundação Oswaldo Cruz (FIOCRUZ), Rio de Janeiro/RJ, Brasil. E-mail: taynamtb@gmail.com

2 Instituto de Estudos Sociais e Políticos (IESP) da Universidade do Estado do Rio de Janeiro (UERJ), Rio de Janeiro/RJ, Brasil. E-mail: pinheiro.leticia14@gmail.com

3 Casa de Oswaldo Cruz (COC) da Fundação Oswaldo Cruz (FIOCRUZ), Rio de Janeiro/RJ, Brasil. E-mail: fpiresalves@gmail.com

Artigo submetido em 12/02/2017 e aprovado em 02/06/2017. 
de mudanças no nível político-administrativo dos ministérios das Relações Exteriores e da Saúde e em menções crescentes ao tema da saúde nos discursos das autoridades brasileiras nos fóruns internacionais.

Palavras-chave: Política Externa Brasileira; Saúde Global; Diplomacia da Saúde.

\begin{abstract}
This article seeks to verify the instrumentality of Health for the active and purposeful participation of Brazil in international politics between 1995 and 2010. The theme provoked complex, constant and striking discussions in several global forums during this period, when the governments of Fernando Henrique Cardoso and Luiz Inácio Lula da Silva sought a relevant and influential international performance. Their governments differed on Brazil's responsibilities and opportunities in the international system, but they shared the goal of assuming a position of influence in international politics. In the strategic search for credibility during FHC mandates and for autonomy in Lula da Silva's period, the country assumed a kind of global duty, which would be carried out through various international partnerships and the participation in relevant global institutions. In this effort, it seemed important to formalize the treatment of Health on the agenda of Brazilian foreign policy. This would provoke a process of institutionalization that resulted in the adoption of changes in the political-administrative levels of the Ministry of Foreign Affairs and the Ministry of Health and in the increasing mention of Health in Brazilian authorities' speeches in international forums between 1995 and 2010.
\end{abstract}

Keywords: Brazilian Foreign Policy; Global Health; Health Diplomacy.

\title{
Introdução
}

O presente artigo objetiva sistematizar o diálogo ocorrido entre as áreas de política externa brasileira e saúde nos governos Fernando Henrique Cardoso (1995-2002) e Luiz Inácio Lula da Silva (2003-2010). Sua ênfase recai sobre a relação entre atuação internacional em saúde e a influência dessa na política internacional, bem como sobre a identificação das formas pelas quais teria ocorrido o processo de institucionalização ${ }^{4}$ do tema da saúde na agenda da política externa brasileira.

4 O termo "institucionalização" é, neste trabalho, entendido como o processo que torna formal a presença da saúde na agenda externa do Brasil. Ou seja, institucionalizar o tema da saúde significa torná-lo tema oficial dessa agenda política, e não um item temporário, informal, de baixa relevância política ou incapaz de mobilizar significativos esforços de implementação. Por meio da institucionalização, a saúde ultrapassa os limites dos "bastidores" da formulação da política externa e passa a ser um tema de caráter sólido, não necessariamente prioritário, mas dotado de atores políticos, mecanismos e espaços político-administrativos próprios. 
Neste trabalho, procuramos identificar o porquê desses governos considerarem importante formalizar o tratamento do tema da saúde na agenda da política externa brasileira. Nossa hipótese é que, em vista de um relativo consenso no plano internacional que ressaltava a importância do tema da saúde na condução das relações internacionais, formou-se a posição de que atuar nessa área ajudaria o Brasil a viabilizar um objetivo central da política externa desse período - fazer do país um ator relevante na política internacional.

A pesquisa que originou este trabalho empreendeu a identificação, reunião e análise qualitativa de materiais bibliográficos e documentais textuais, primários e secundários. Foram considerados materiais primários aqueles produzidos pelos atores no momento de sua presença e ação em uma dada circunstância histórica. Em grande medida, são partes integrantes dessas ações e de suas decorrências imediatas e, a partir deles, é possível estabelecer uma relação direta com os eventos a serem analisados. As fontes primárias utilizadas consistiram em discursos dos presidentes da República, de ministros da Saúde e de ministros das Relações Exteriores, programas de governo, acordos internacionais firmados pelo Brasil e relatórios dos Ministérios da Saúde e das Relações Exteriores, além de publicações da Agência Brasileira de Cooperação, da Assessoria de Assuntos Internacionais em Saúde, da Fundação Oswaldo Cruz e da Organização das Nações Unidas. Nos documentos da área de política externa, o estudo buscou identificar as ocorrências e o sentido atribuído às menções ao tema da saúde. Nos documentos provenientes das autoridades em saúde, por sua vez, foram observados o registro e o grau de relevância atribuídos às atividades internacionais. Buscou-se também identificar elementos que evidenciassem o processo de institucionalização da saúde como tema da política externa brasileira.

Como fontes secundárias, por sua vez, foram considerados os materiais que discorrem sobre os eventos e processos que estão sendo observados. Apresentam distanciamento temporal, tendendo mais fortemente à produção de narrativas e análises a posteriori, ou reúnem informações que já foram processadas por outros estudiosos e configuram parte de um acervo de conhecimentos acerca de um dado tema (Sá-Silva, Almeida, Guindani, 2009). A análise dos documentos oficiais foi realizada a partir das contribuições de literatura secundária especializada e variada no que concerne à emergência de questões como direitos humanos, meio ambiente e saúde, entre outros temas da política internacional; à análise de política externa e à evolução recente da diplomacia brasileira, assim como o lugar, nela atribuído, à saúde; e às transformações experimentadas por estruturas 
organizacionais relevantes para os objetivos propostos, como o Ministério das Relações Exteriores, o Ministério da Saúde e suas agências. Essas fontes incluíram a literatura referente à Relações Internacionais, Saúde Global, Diplomacia em Saúde e Política Externa Brasileira. Essas referências foram identificadas mediante levantamento não sistemático. São obras monográficas, capítulos de coletâneas e artigos publicados em periódicos internacionais e nacionais, como The Lancet, International Organization, Revista Eletrônica de Comunicação, Informação \& Inovação em Saúde, Cadernos de Saúde Pública, Revista Brasileira de Política Internacional e Contexto Internacional, além de obras de literatura clássica e recente, de autores como Cervo \& Bueno, Vigevani \& Cepaluni e David Fidler, entre outros.

Analisando o tratamento formal do tema da saúde na agenda de política externa brasileira, este artigo contribui para o conhecimento acerca do diálogo entre diplomacia e saúde no país, tema que, apesar do crescente interesse na área de Relações Internacionais e nos estudos multidisciplinares sobre saúde global e diplomacia em saúde, ainda conta com pouca atenção no meio acadêmico brasileiro.

\section{0 contexto internacional e o objetivo da política externa brasileira}

O fim da Guerra Fria e a intensificação da globalização marcam a configuração de uma nova realidade internacional. A influência da ideologia neoliberal, a formação de blocos econômicos, o crescimento das assimetrias entre o centro do capitalismo e sua periferia, o desenvolvimento de economias emergentes, o diversificado fluxo de informações, a intensificação das interações temporais e espaciais e o crescimento da sociedade civil organizada são algumas das mudanças que caracterizam esse cenário. Na década de 1990, a política externa brasileira buscava se adaptar a esse novo contexto. Novos temas, tais como meio ambiente, direitos humanos e saúde; e novos atores, como organizações não governamentais, assim como novos espaços de diálogo multilateral, influenciavam a condução da política internacional, exigindo do Brasil a atualização de sua atuação nesse cenário. Assim, a diplomacia brasileira passou a incentivar o diálogo entre desenvolvimento e temas globais, como demonstram as participações na Conferência sobre Meio Ambiente e Desenvolvimento (Rio-92), na Conferência Mundial sobre Direitos Humanos de Viena (1993) e nos debates da Organização Mundial do Comércio - OMC (Cervo, Bueno, 2011). 
A globalização reafirmou a articulação entre saúde e política externa de forma significativa, oferecendo novos atores, mecanismos e espaços de relacionamento. Permitiu o fortalecimento da percepção de que as questões de saúde exigiam iniciativas de escopo global, uma vez que esse era o caráter das ameaças às condições de saúde das populações. A partir desse reconhecimento, a saúde ganhou importância nos processos de formulação de políticas externas, sendo considerada um instrumento significativo para a promoção de interesses e princípios nacionais na política internacional. Essa nova articulação pode ser observada por meio de algumas constatações, entre outras: a) os acordos de governança adotados pela OMS, como o Regulamento Internacional em Saúde (2005) e a Convenção-Quadro de Controle do Tabaco (2003); b) os novos mecanismos, iniciativas e parcerias em saúde global, como o Fundo Global de Combate à aids, Tuberculose e Malária e a Aliança Global para Vacinas e Imunização (GAVI); c) a proliferação de atores atuantes nessa área, incluindo países emergentes e organizações governamentais e não governamentais importantes para as questões de saúde (Fidler, 2009). Entre 1995 e 2010, as condições de saúde no mundo eram inegavelmente desafiadoras e, apesar de alguns resultados positivos, as políticas em saúde ainda demandavam incontáveis esforços internacionais e engajamento nas questões de acesso a medicamentos e serviços, fortalecimento de sistemas de saúde e capacitação profissional em saúde, entre outras.

Nesse contexto, se dava a atuação internacional do Brasil em defesa da saúde. Discutir a saúde em fóruns globais, desenvolver e apoiar projetos duradouros na área, promover parcerias e contribuir para abordagens inovadoras no combate a doenças eram formas de tratar a saúde de maneira formal e estratégica, fortalecendo a sua presença na diplomacia brasileira que, dessa forma, tinha na saúde um instrumento valioso para o alcance de uma atuação internacional relevante e de destaque. Entre 1995 e 2010, a política externa brasileira lidou com a saúde como um direito humano absoluto, que renovava a agenda diplomática diante do novo cenário internacional do pós Guerra Fria e era fundamental para o discurso de progresso e equidade internacionais que se desenvolvia. As percepções dos governos de Fernando Henrique Cardoso (FHC) e Luiz Inácio Lula da Silva divergiam sobre as possibilidades do cenário internacional e a dimensão dos recursos de poder brasileiros, mas convergiam no objetivo de que o país tivesse uma atuação mais relevante na política internacional.

Em pesquisa realizada, em 2001, por Amaury de Souza, autoridades governamentais, líderes de organizações não governamentais, empresários, 
acadêmicos e jornalistas, num total de 149 entrevistados, defenderam o papel de liderança do Brasil no sistema internacional, o que seria respaldado pelo território de dimensões continentais e pela competência da sua diplomacia. Cerca de $90 \%$ dos participantes declararam que, nos dez anos seguintes, a influência internacional do país seria ainda maior, reafirmando essa aspiração (Souza, 2002)5. Entre 1995 e 2010, a atualização da agenda de política externa, o diálogo com parceiros diversificados, o fortalecimento da capacidade de negociação, as contribuições políticas para as discussões globais e a tendência a conciliar divergências internacionais reafirmavam o objetivo de ambos os governos de aumentar sua influência.

\section{Governo Fernando Henrique Cardoso: a participação como estratégia de política externa}

É possível pensar a política externa brasileira do governo FHC como um tipo de atualização do país frente aos regimes e normas internacionais vigentes, a partir da qual o país poderia vir a influenciar o debate global, desenvolvendo uma participação propositiva na política internacional e contribuindo para a formação e a regulamentação da nova ordem internacional. Esse governo considerava o Brasil como um país de poderes intermediários e que, por isso, não deveria assumir grandes responsabilidades ou riscos excessivos no cenário internacional, percebido como constrangedor e de significativas assimetrias de poder. A atuação deveria ser moderada, conciliatória, seguidora do Direito Internacional, ativa nos fóruns globais, defensora do multilateralismo e coerente com os regimes internacionais (Vigevani, Oliveira, 2003; Pinheiro, 2004). A orientação central era a de abrir o Brasil ao mundo, intensificando a integração regional, especialmente na América do Sul, diversificando parceiros nas relações bilaterais, sobretudo com os países desenvolvidos, e atuando nos espaços multilaterais, principalmente na OMC. Assim, buscava-se, segundo tal lógica, garantir autonomia nacional, respaldo para os interesses brasileiros, credibilidade e confiança no sistema internacional.

5 Segundo Lima (2005, p. 8), a aspiração brasileira por participação ativa na política internacional é constitutiva da própria identidade nacional, “já que a percepção que as elites têm da identidade nacional constitui o substrato conceitual de sua projeção externa, pautada principalmente no desejo de exercer um papel protagônico”. Tanto a percepção de identidade como a expectativa de liderança se desenvolvem a partir da consideração de que território continental, grande população, economia diversificada, dez vizinhos contíguos e uniformidade cultural e linguística fazem do Brasil um "grande país” com um "grande papel” a desempenhar no cenário internacional, sendo esse, portanto, o objetivo central de sua política externa. 
Nesse período, o cenário internacional era visto como um ambiente desfavorável, no qual a diplomacia brasileira deveria atuar a longo prazo, buscando adaptar-se às mudanças e fortalecendo o diálogo multilateral como padrão de ação coletiva (Vigevani, Oliveira, 2003). Em vista da alegada comunhão de valores entre o Brasil e o mainstream internacional, e apesar de possuir poderes apenas medianos, o país não poderia se eximir da participação nas discussões globais. Essa postura é interpretada por Vigevani \& Cepaluni (2007) como baseada numa lógica de “autonomia pela participação”, pela qual o Brasil desenvolveria uma agenda diplomática proativa, ampliando o controle sobre o seu destino, reafirmando o poder nacional e colaborando para a regulamentação das relações internacionais, nas mais diversas áreas. Assim, a inserção do Brasil no sistema internacional, como um ator confiável, estável, seguidor das regras e regimes internacionais e, ao mesmo tempo, influente na formulação dos princípios e normas da ordem internacional, consistiria no objetivo central da política externa.

Já de acordo com Cervo (2003), é possível identificar quatro grandes eixos na política externa brasileira do governo de FHC: a) o multilateralismo como a força capaz de fomentar a formulação mundial de regras justas, transparentes e respeitadas por todos, que estimulariam um comércio internacional sem barreiras, a proteção do meio ambiente aliada ao desenvolvimento e um regime de segurança regido pela Organização das Nações Unidas (ONU); b) o regionalismo, pelo qual o Brasil iria alcançar compensações econômicas e reforçar o seu poder político; c) a relação com os Estados Unidos, que ocorreria de forma ambígua, com a alternância entre certa subserviência na dimensão econômica e confronto na dimensão política; e d) o diálogo com a União Europeia, o qual, mesmo sem resultados concretos, buscaria uma zona de livre comércio a fim de equilibrar as relações com os Estados Unidos no que concerne à Área de Livre Comércio das Américas (ALCA), proposta pelo presidente Bill Clinton em 1994. Esses eixos teriam caracterizado a década de 1990 como a década das ilusões, uma vez que, na prática, ao invés de ampliar as margens de atuação do Brasil no mundo, as teria limitado.

\section{Governo Luiz Inácio Lula da Silva: a transformação como estratégia de política externa}

No contexto de uma nova fase da globalização, na qual a ideologia neoliberal perdia importância na periferia e os países emergentes fortaleciam seus mecanismos de articulação entre si (IBAS, G-20, BRICS), o governo do presidente Lula da 
Silva atualizava a agenda da política externa brasileira investindo na defesa da redistribuição do poder nas relações internacionais. O cenário internacional representava um espaço de oportunidades para o fortalecimento da capacidade negociadora do Brasil, para a diversificação de suas parcerias, a criação de fóruns internacionais, a mediação das relações entre países desenvolvidos e em desenvolvimento e a defesa de temas sociais nas discussões globais (Cervo, Bueno, 2011). A diretriz central era, portanto, aumentar o espaço de atuação do Brasil no mundo. $\mathrm{O}$ aprofundamento da integração sul-americana, o estreitamento das relações com a África e a defesa da reforma do Conselho de Segurança da ONU foram algumas das medidas que visavam a construção de uma ordem internacional mais igualitária e justa.

Cervo (2003) identifica quatro grandes linhas de força na condução da política externa brasileira no governo do presidente Lula da Silva: a) recuperação do universalismo e do bilateralismo, a partir de parcerias estratégicas com a África, a China, o Japão e a Rússia e da reivindicação de um assento permanente no Conselho de Segurança da ONU; b) relação com a América do Sul, considerada o espaço natural de afirmação dos interesses brasileiros, reforço das economias da região, autonomia na dimensão política e rejeição a intervenções externas em caso de problemas de segurança regional; c) fim de dependências estruturais e promoção de uma inserção interdependente, a fim de combater a vulnerabilidade externa e amenizar os efeitos negativos da globalização assimétrica sobre o Brasil e os países em desenvolvimento e; d) preservação do acumulado histórico da diplomacia brasileira, assegurando o respeito aos princípios de autodeterminação, não intervenção, pacifismo e desenvolvimento.

No mesmo sentido, Vigevani, Cepaluni (2007) identificam algumas diretrizes adotadas na condução da política externa do governo de Lula da Silva, como a busca por maior equilíbrio no sistema internacional, o fortalecimento do intercâmbio econômico, financeiro, tecnológico e cultural por meio da diplomacia e a participação influente do país em negociações multilaterais e bilaterais. Esses mesmos autores atribuem ao governo Lula da Silva a busca de "autonomia pela diversificação”, pela qual o governo procurava formas autônomas de relacionamento internacional, capazes de envolver diversos parceiros, especialmente os do Sul, em múltiplos arranjos, e de permitir distintas opções estratégicas para a diplomacia brasileira, o que aumentaria a sua capacidade negociadora, equilibraria as relações com o Norte e aumentaria o protagonismo internacional do país. 
A aspiração brasileira de democratizar as relações internacionais é discutida por Parola (2007, p. 30), que atribui à política externa do governo do presidente Lula da Silva a ideia de "pragmatismo democrático”, considerando-a uma "política que articula a promoção de valores inspirados pela própria cidadania com a capacidade de atuar de modo não dogmático em defesa dos interesses nacionais e da construção de uma ordem justa”. Nesse sentido, é possível dizer que a política externa brasileira desse governo era guiada por valores que consideravam o país como uma potência em construção e defendia uma perspectiva humanista sobre a ordem internacional, na qual os compromissos de justiça, igualdade e democracia deveriam ser buscados pelos países.

Apesar das diferenças de ênfase e mesmo de princípio na política externa dos governos de FHC e Lula da Silva, o Brasil desenvolveu, como veremos a seguir, uma diplomacia propositiva e influente no debate internacional em saúde, capaz de formular diretrizes para a regulação internacional, apresentar ao mundo as experiências nacionais e estabelecer escolhas que reforçavam seu papel de liderança no cenário internacional.

\section{A atuação internacional do Brasil em saúde}

De forma ainda incipiente e enfrentando as dificuldades de comunicação e troca de conhecimento, entre 1995 e 1999, o Brasil buscava parcerias com China, Índia e Rússia na área da saúde (Rubarth, 1999). Em 1995, o país participou, em Copenhague, do primeiro grande evento internacional sobre o tema do desenvolvimento social, a Cúpula Mundial sobre Desenvolvimento Social, que estabeleceu compromissos que envolviam a erradicação da pobreza, o respeito à dignidade humana e o acesso universal à educação e à saúde, entre outros. No mesmo ano, o país contribuiu para a discussão internacional em saúde ao participar da IV Conferência Mundial sobre a Mulher, em Pequim, na qual a extensa delegação brasileira foi composta por diplomatas e um representante do Ministério da Saúde, entre outros atores, que discutiram as desigualdades no acesso aos serviços de saúde e a violência contra a mulher (Alves, 2001). Ainda no âmbito da Organização das Nações Unidas, o lançamento dos Objetivos de Desenvolvimento do Milênio, em 2000, chancelados pelos 191 membros da Organização, também representou um momento importante para a discussão internacional em saúde e a política externa brasileira nessa área. Três dos oito 
objetivos referem-se explicitamente ao tema da saúde, na defesa da promoção da saúde das gestantes, da redução da mortalidade infantil e do combate à aids, malária e outras doenças (BRASIL, 2014).

A participação do Brasil nos grandes debates internacionais em saúde também aumentou de forma significativa, inclusive em fóruns como o da OMC. Em fevereiro de 2001, acusado pelos Estados Unidos de violar o Acordo TRIPS, o Brasil mobilizou uma série de atores internacionais em benefício das demandas dos países em desenvolvimento, enfatizando as necessidades social e econômica de se preservar a disponibilidade de medicamentos genéricos para o tratamento de pessoas com HIV/Aids nesses países e destacando os preços exorbitantes praticados pela indústria farmacêutica norte-americana. O país obteve o apoio de vários países; da opinião pública internacional; de importantes organizações não governamentais, como Médicos Sem Fronteiras e Oxfam Internacional; da ONU; e da OMS, todos em defesa do acesso a medicamentos (Ponte, 2012). Meses depois, em junho de 2001, os Estados Unidos retiraram sua queixa na OMC, em troca da garantia de que seriam notificados, com antecedência, caso qualquer produto patenteado ou licenciado por empresas norte-americanas fosse licenciado compulsoriamente pelo Brasil (Souza, 2011). O episódio conhecido como "contencioso das patentes farmacêuticas" ilustraria a forte influência brasileira no debate internacional em saúde, que mobilizava atores e estruturas de governança internacionais importantes (Cepaluni, 2005).

Em abril de 2001, foi aprovada, na Comissão de Direitos Humanos da ONU, a resolução "Acesso a Medicamentos no Contexto de Pandemias como HIV/Aids", que apresentava o acesso a medicamentos essenciais como um direito humano à saúde. Foi proposta pela delegação brasileira e aprovada por 52 países. Em seguida, na Assembleia Mundial da Saúde (AMS), em maio do mesmo ano, o país reafirmava a necessidade de redução dos custos dos medicamentos antirretrovirais, defendia a produção de genéricos em países pobres e a elaboração de um fundo internacional para o financiamento de projetos de combate à aids nesses países. A "Resposta Global ao HIV/Aids" e a "Estratégia de Medicamentos da OMS" foram duas resoluções que resultaram das propostas brasileiras (Souza, 2011). Em novembro de 2001, na IV Conferência Ministerial da OMC, em Doha, o Brasil liderou as críticas ao Acordo TRIPS, defendendo a flexibilização de alguns de seus termos e a proteção da saúde pública diante dos interesses econômicos dos grandes laboratórios. Novamente, em consonância com o debate internacional, o país contou com o apoio de ativistas de inúmeros países. Com a liderança 
brasileira, a Conferência produziu a “Declaração sobre o Acordo TRIPS e a Saúde Pública”, que formalizou a busca de mecanismos que protegessem a saúde pública, promovessem o acesso a medicamentos, reduzissem os efeitos negativos do Acordo TRIPS e colaborassem para a difusão de conhecimentos (Souza, 2011).

A participação do Brasil na elaboração da Convenção-Quadro de Controle do Tabaco é outro destaque de sua atuação internacional em saúde. Com início em 2000 e reunindo representantes dos Estados-membros da OMS, de organizações internacionais e de dezenas de organizações não governamentais, as reuniões do Órgão de Negociação Intergovernamental, responsável pela elaboração do texto da Convenção-Quadro, foram presididas pelos embaixadores brasileiros Celso Amorim e Luiz Felipe Correa durante todo o período de elaboração do texto. A aprovação oficial durante a AMS de 2003 dava origem ao primeiro tratado internacional de iniciativa da OMS com a missão de reduzir mortes e doenças ligadas ao tabaco em todo mundo (Toscano, 2006).

Seguindo as discussões sobre os preços de antirretrovirais patenteados, o presidente Lula da Silva promulgou, em 2003, o Decreto $n^{\circ} 4.830$, que permitia a importação de medicamentos genéricos de produtos licenciados compulsoriamente sempre que a produção doméstica fosse considerada inviável, obrigando o detentor da patente a apresentar toda a informação necessária para a produção. Por meio desse decreto, o poder de barganha brasileiro diante das grandes companhias farmacêuticas, como Merck, Roche, Abbott e Gilead, foi fortalecido, e significativas vitórias foram alcançadas no que concerne à compra de medicamentos (Souza, 2011).

Na 56 AMS, também em 2003, o Brasil defendeu a ideia de que a OMS deveria dispor de um mandato que lhe permitisse avaliar as implicações, para a saúde pública, da proteção dos direitos de propriedade intelectual, como acordados no Acordo TRIPS. Nesse contexto, o país votou a favor da Resolução N ${ }^{0} 56.27$, “Direitos de Propriedade Intelectual, Inovação e Saúde Pública”, que reivindicava que a OMS adotasse medidas para a redução dos efeitos negativos dos acordos internacionais de comércio (Souza, 2011). Já na 57 a AMS, em 2004, foi aprovada a Resolução $N^{\circ}$ 57.14, que reafirmou o direito dos países membros da OMS de utilizar as flexibilidades do TRIPS e de acordos de comércio regionais e bilaterais, destacando a urgência do acesso a medicamentos.

Expressão da crescente importância do tema na agenda diplomática do país, a assinatura, em julho de 2005, do Protocolo de Intenções entre o ministro das Relações Exteriores e o ministro da Saúde (BRASIL, 2005), instituindo coordenação 
entre os dois órgãos para o aperfeiçoamento da cooperação técnica em saúde prestada pelo Brasil a países em desenvolvimento, representou um marco para a relação entre os dois ministérios e para a atuação internacional do Brasil em saúde. A partir de 2005, a relação com os Países Africanos de Língua Oficial Portuguesa foi fortalecida e, em 2008 e 2009, ocorreram as Reuniões dos Ministros de Saúde da Comunidade de Países de Língua Portuguesa, que permitiram a formulação e a aprovação das parcerias em saúde, que previam a construção e o fortalecimento de iniciativas "estruturantes", o desenvolvimento de políticas de vigilância epidemiológica e o reforço dos sistemas de saúde desses países, entre outras atividades (Almeida et al., 2010). É válido ressaltar que, durante o governo do presidente Lula da Silva, a África apresentou o maior número de iniciativas em saúde, totalizando 53 atos bilaterais com 22 países (BRASIL, 2010a). Em 2006, o Brasil, ao lado de Chile, França, Noruega e Reino Unido, na Assembleia Geral da ONU, se tornava membro fundador da UNITAID, uma iniciativa global que arrecada recursos para o diagnóstico, a prevenção e a compra de medicamentos para o tratamento da aids, da malária e da tuberculose em países em desenvolvimento.

Outro documento de significativa relevância, nesse breve histórico de medidas brasileiras que promoveram sua participação no debate internacional em saúde, foi assinado na Noruega, em 2007, envolvendo, além do Brasil, os ministros de Relações Exteriores da França, Indonésia, Noruega, África do Sul, Tailândia e Senegal. Pela Declaração de Oslo, esses ministros defendem explicitamente a saúde como um tema de política externa e de importância fundamental para a agenda do desenvolvimento, clamando por uma ação global em benefício da saúde (Amorim et al., 2007).

Em março de 2007, o Ministério da Saúde criou o programa "Mais Saúde — Direito de Todos", para o período de 2008 a 2011. Um dos seus sete eixos de trabalho consiste na cooperação em saúde com outros países, a fim de fortalecer a atuação internacional do Brasil, especialmente nos programas da ONU, e estreitar o diálogo com o MRE, colaborando para o desenvolvimento dos sistemas de saúde dos países parceiros, apoiando, inclusive, o estabelecimento de uma rede pan-amazônica de cooperação em ciência, tecnologia e inovação e a formação profissional de técnicos em saúde. Um dos resultados desse programa consistiu no desenvolvimento - pela Rede Brasileira de Bancos de Leite Humano, coordenada pelo Ministério da Saúde - de iniciativas que proporcionaram a implantação de 21 bancos de leite humano em seis países, entre 2007 e 2009 (BRASIL, 2010b). 
A Resolução WHA60.30, "Saúde Pública, Inovação e Propriedade Intelectual”, aprovada na $60^{\mathrm{a}}$ AMS de 2007, resultou, em grande medida, dos esforços brasileiros para que a OMS assumisse o compromisso de apoiar tecnicamente os países que desejassem utilizar as flexibilidades do Acordo TRIPS (Souza, 2011). Nesse ano, o país também emitiu licença compulsória para o antirretroviral Efavirenz, da Merck, sendo o primeiro caso de licenciamento compulsório de um antirretroviral no continente americano.

Em 2008, na Cúpula da Costa do Sauípe, foi criado o Conselho Sul-Americano de Saúde, pelo qual a União das Nações Sul-Americanas expandia o programa de cooperação em saúde na região. Suas atividades previam o estabelecimento de um escudo epidemiológico nesses países, o desenvolvimento de sistemas de saúde universais, o acesso universal a medicamentos, a capacitação de recursos humanos, entre outras atividades (Almeida et al., 2010). No âmbito da Unasul, o país liderou o processo de decisão pela criação, em 2009, e pela instalação, no Rio de Janeiro, do Instituto Sul-Americano de Governo em Saúde (ISAGS), um centro de altos estudos e de debate dos temas da saúde sul-americana.

Seguindo na defesa do acesso a medicamentos, o Brasil, junto com os parceiros do IBAS e com o apoio de vários países em desenvolvimento, aprovou, em 2009, no Conselho de Direitos Humanos da ONU, a Resolução Nº 6/29, que reconhece o acesso a medicamentos como elemento fundamental para o alcance de altos padrões de saúde física e mental e destaca o papel dos Estados para a garantia da oferta de medicamentos (Souza, 2011).

O número e variedade dessas iniciativas, no período estudado, que transitam da disputa de contenciosos no terreno das patentes de medicamentos à oferta de cooperação técnica em um número expressivo de países, de pelo menos dois continentes, passando pela celebração de acordos, a presença ativa em fóruns internacionais e o eventual protagonismo na criação de algumas dessas instâncias, sinalizam para um contínuo aumento da importância do tema da saúde na agenda internacional do país. O presidente FHC, seguindo sua política de autonomia pela participação, fortaleceu uma política inovadora de acesso a medicamentos para a aids, o que influenciou países desenvolvidos e em desenvolvimento. Associando a saúde ao tema de direitos humanos, esse governo atualizava a diplomacia brasileira diante das mudanças do cenário internacional pós Guerra Fria, dirimindo divergências internacionais e influenciando o debate global em saúde. No governo de Lula da Silva, o país contribuiu para as discussões globais em saúde por meio de sua experiência na área e sua disposição para desenvolver e executar projetos 
internacionais relacionados, especialmente os que atendessem às necessidades das populações dos países em desenvolvimento. Nesse sentido, o presidente deu continuidade e promoveu a política externa para a aids, a defesa de acesso a medicamentos e redução de preços para o tratamento de doenças negligenciadas, como malária e tuberculose, e o discurso que aliava a saúde ao tema de direitos humanos. A saúde das populações era um dever global que o Brasil deveria cumprir por meio de diversas parcerias internacionais e pela participação nas instituições globais, como a Organização Mundial da Saúde e a OMC.

Tanto pela promoção do direito internacional e da participação brasileira nos regimes globais, como mostra o período de 1995 a 2002, quanto pelo fortalecimento do diálogo com os países em desenvolvimento e a reafirmação da liderança brasileira no Sul, como visto entre os anos de 2003 a 2010, os presidentes brasileiros seguiram uma linha de ação pela qual o país influenciou as discussões internacionais e apresentou ao mundo sua experiência, colaborando para a regulação internacional em saúde e a execução de projetos de cooperação nessa área.

Na literatura acadêmica, há autores que defendem que as mudanças entre as políticas externas dos presidentes FHC e Lula da Silva foram significativas (Cervo, Bueno, 2011; Parola, 2007). Do outro lado, estão aqueles que afirmam que o presidente petista apenas seguiu as linhas de atuação estabelecidas por seu antecessor (Pecequilo, 2008). Há ainda uma corrente em posição intermediária que atribui à gestão do presidente Lula da Silva ajustes, mudanças e continuidades (Vigevani, Cepaluni, 2007; Vaz, 2004; Saraiva, 2007). É possível afirmar que essas classificações variam de acordo com os momentos e objetos de análise. O tema da saúde, em específico, não só estava presente na agenda da política externa brasileira em ambos os governos, como também essa presença se desenvolveu em um processo crescente de institucionalização, tanto em termos político-administrativos, quanto no nível do discurso, o que oferece uma dimensão de continuidade entre eles, respeitando as diferenças, sem dúvida existentes, nos esforços diplomáticos e linhas de atuação de cada governo em uma outra ordem de iniciativas.

\section{A institucionalização da saúde na política externa brasileira}

Alcázar (2005) considera que a institucionalização do tema da saúde na agenda da política externa brasileira é resultado de vários fatores, como a implantação do Sistema Único de Saúde (SUS); o fortalecimento do Ministério da Saúde como ator político, que passou a participar dos encontros da OMC e da Assembleia 
Geral da ONU e de outros fóruns não relacionados diretamente à saúde, além das reuniões da OMS e da Organização Pan-Americana da Saúde (OPAS); as melhores disponibilidades orçamentárias para esse órgão; e a emergência dos temas sociais nas discussões internacionais.

Por outro lado, a intenção de participar do debate internacional em saúde também se materializou por meio de um processo de institucionalização no tratamento desse tema pela política externa brasileira, evidenciado pelas modificações no nível político-administrativo e no discurso oficial. Em favor do fortalecimento da atuação internacional do Brasil no campo da saúde e, portanto, de sua participação nos fóruns globais e de influência na formulação de políticas, foi necessário introduzir mudanças nas estruturas organizacionais do MRE e do Ministério da Saúde, em seus mecanismos de diálogo e atuação, além de ser indispensável que o país afirmasse seu compromisso internacional com o tema por meio de declarações oficiais das autoridades brasileiras.

Em 1995, o Ministério das Relações Exteriores criou o “Departamento de Direitos Humanos e Temas Sociais”, que seria responsável pela participação do Brasil nas conferências sociais internacionais da década de 1990. Alterava-se, assim, a estrutura da Subsecretaria Geral Política I desse ministério, que não mais trataria dos temas sociais apenas como parte subordinada das atribuições de uma divisão (Puntigliano, 2008). No mesmo sentido, uma década depois, a Agência Brasileira de Cooperação (ABC), vinculada ao MRE, e possuindo as funções principais de operacionalizar a política de cooperação técnica internacional do país e de elaborar e monitorar os projetos de cooperação prestados e recebidos pelo Brasil, passou a adotar, em 2006, uma divisão temática, não mais geográfica, para sua organização interna. Em 2007, seria instituída a Coordenação-Geral de Cooperação em Saúde, Desenvolvimento Social, Educação e Formação Profissional, que passaria a orientar as contribuições do MRE para os projetos internacionais do país em saúde (ABC, 2010).

Em relatório próprio, divulgado em 2009, a Assessoria de Assuntos Internacionais em Saúde (AISA), vinculada ao Ministério da Saúde, explicitou a necessidade de reorganização político-administrativa desse ministério em nome das contribuições à formulação de política externa na área da saúde. Nesse relatório, a assessoria declarou que as ações internacionais do Ministério da Saúde deveriam seguir os propósitos maiores da política externa brasileira, em diálogo estreito com os seus órgãos vinculados, como a Fiocruz e a Anvisa, e com o MRE. Como também defendido pela ABC, o diálogo entre os dois ministérios deveria incluir a troca de profissionais e a criação de mecanismos de articulação, 
em benefício do fortalecimento da atuação diplomática do Brasil no mundo, no qual as novas agendas diplomáticas requeriam a troca de expertise entre diversas áreas especializadas (BRASIL, 2009a).

O relatório também aponta que, pela resolução "Saúde e Relações Internacionais: vinculações com o desenvolvimento sanitário nacional do Comitê Executivo da Opas/OMS", assinada em junho de 2008, o país reafirmou a ideia de interação entre as "autoridades sanitárias" e as "autoridades encarregadas da política exterior", por meio do reforço dos mecanismos institucionais de diálogo e da inclusão tanto do tema da saúde na profissionalização dos diplomatas quanto dos temas de relações internacionais na formação das autoridades em saúde (BRASIL, 2009a, p. 5).

O mecanismo de transferência internacional de recursos, chamado Termo de Cooperação No 41 (TC-41), assinado em 2005 pelo Ministério da Saúde e a Opas/OMS, também estimulou a parceria entre o Ministério da Saúde e o MRE na elaboração das ações internacionais em saúde, na medida em que as partes signatárias reconheciam expressamente a necessidade de colaboração e articulação entre as duas pastas (BRASIL, 2006). Esse mecanismo pressupunha que o país se constituía em referência para a cooperação internacional na área da saúde e tinha como objetivo central promover a troca de experiências, tecnologias e conhecimentos pelas instituições brasileiras no âmbito da cooperação Sul-Sul. As atividades previstas incluíam pesquisa básica, ações em saúde coletiva, produção de insumos, análise de políticas públicas e história da saúde, entre outras (Pires-Alves; Paiva; Santana, 2012).

Se as informações acima apontam para os arranjos de natureza político-administrativa que foram ao mesmo tempo causa e efeito da relevância do tema da saúde na agenda da política externa brasileira, no nível do discurso oficial devem ser consideradas todas as referências a eventos internacionais em saúde disponibilizados pelos websites do Ministério das Relações Exteriores e do Ministério da Saúde. Os resultados mostram então a proeminência da participação dos presidentes FHC e Lula da Silva e dos responsáveis pelas pastas da saúde e das relações exteriores nos fóruns internacionais. Em todos os documentos, é possível observar a importância conferida, por essas autoridades, ao tema da saúde na diplomacia brasileira em sua busca pelo fortalecimento do país como ator político internacional relevante. Notou-se também o apoio à parceria entre o MRE e o Ministério da Saúde, mencionada como responsável por parte significativa do sucesso da atuação internacional do país em saúde. Já a variedade de fóruns em que os discursos foram proferidos pode ser atribuída ao reconhecimento, pelas 
autoridades brasileiras, do diálogo da saúde com outras dimensões da política externa, como segurança, desenvolvimento e direitos humanos.

Assim, nas Assembleias-Gerais das ONU, na Cúpula das Américas, nas Assembleias Mundiais da Saúde, na Cúpula África-América do Sul ou em colóquios e congressos internacionais sobre saúde desde 2001, o Brasil declarou o seu apoio a políticas de acesso a medicamentos e de tratamento de doenças negligenciadas, como malária e tuberculose; discorreu sobre sua experiência no tratamento da aids; reafirmou o seu compromisso com os países em desenvolvimento e o combate à pobreza; ressaltou a necessidade de expansão da produção de conhecimento; e defendeu a equidade, a melhoria dos sistemas de saúde ao redor do mundo e a capacitação dos profissionais dessa área. A seguir, apresentamos alguns trechos de discursos oficiais.

Nos dois primeiros, o presidente FHC, em tom conciliatório e de acordo com um estilo de política externa moderado, discorreu sobre a internacionalização da experiência brasileira no tratamento da aids e sobre a posição do país em defesa do acesso a medicamentos. A partir de ambos os exemplos, constata-se que o Brasil pretendia assumir um papel de ator influente no debate internacional sobre o tema da saúde.

Primeiramente, em abril de 2001, no Canadá, por ocasião da III Reunião de Cúpula das Américas, FHC declarou:

Pelo diálogo e pela cooperação poderemos responder a desafios contemporâneos, como o de assegurar aos que sofrem com a AIDS tratamento ao menor custo possível. Como demonstra o êxito do programa brasileiro nesse campo, já dispomos de meios para aumentar a esperança e melhorar a vida dos que têm o vírus HIV. Não podemos deixar de utilizá-los, e de utilizá-los em toda a escala, inclusive cooperando com outros países em desenvolvimento afetados por essa doença. (BRASIL, 2009b)

Em seguida, em novembro de 2001, na Abertura do Debate-Geral da 56 a Sessão da Assembleia-Geral das Nações Unidas, o presidente afirmou:

O Brasil, que vem liderando negociações para garantir maior acesso aos mercados e melhores condições humanitárias para o combate às doenças, buscará encontrar o ponto de equilíbrio entre a necessária preservação dos direitos de patente e o imperativo de atender aos mais pobres. Somos pelas leis de mercado e pela proteção à propriedade intelectual, mas não ao custo de vidas humanas [...] A vida há de prevalecer sobre os interesses materiais. (BRASIL, 2009b) 
No decorrer do processo de institucionalização do tema da saúde na agenda da política externa brasileira, o Brasil passaria a reconhecer o diálogo desse tema com outras dimensões da diplomacia. A consideração das epidemias como ameaças à segurança dos países pode ser observada na seguinte declaração do Ministro Celso Amorim.

Em outubro de 2003, na Cidade do México, no Debate-Geral da Conferência Especial de Segurança da Organização dos Estados Americanos sobre justiça social, o Ministro declarou:

Diretamente ou não, todas nossas sociedades sofrem os efeitos da criminalidade, da corrupção, da lavagem de dinheiro, do fácil acesso legal ou ilegal - às armas de fogo, do tráfico de menores, da delinquência pelas drogas, dos delitos ambientais, das epidemias de elevado impacto social, como a da AIDS, ela própria considerada uma ameaça à segurança internacional pelas Nações Unidas. (AMORIM, 2003)

O sentido de continuidade entre os governos de FHC e Lula da Silva, no que concerne a uma ativa atuação internacional em saúde, pode ser identificado nas ações de combate à aids. Nos dois fragmentos seguintes, o presidente Lula reafirmou o empenho internacional do Brasil no tratamento dessa doença e no compartilhamento da experiência nacional nessa área. Seguindo a defesa, iniciada nos anos de 1990, dos direitos humanos, Lula da Silva, como seu antecessor, mas em um contexto internacional diferente e formulando de forma distinta a política externa brasileira, enfrentou as ameaças das regulações de patente.

Em setembro de 2004, em Nova York, por ocasião da LIX Assembleia-Geral das Nações Unidas, o presidente Lula da Silva afirmou:

Acredito firmemente que o processo desencadeado ontem elevará o patamar da luta contra a pobreza no mundo. Na medida em que avançarmos nessa nova aliança, teremos melhores condições de cumprir as Metas do Milênio, sobretudo a erradicação da fome [...] Foi com esse espírito que África do Sul, Índia e Brasil estabeleceram, no ano passado, o fundo de solidariedade - IBAS. Nosso primeiro projeto, em Guiné-Bissau, será lançado amanhã. Também priorizamos o tema do HIV-AIDS, que tem perversa relação com a fome e a pobreza. Nosso programa de Cooperação Internacional no combate ao HIV-AIDS já opera em seis países em desenvolvimento e brevemente chegará a mais três. (BRASIL, 2008) 
Em julho de 2005, em Paris, na Abertura do Colóquio “Brasil: Ator Global” sobre o papel do Brasil no mundo globalizado, o presidente afirmou:

Um país como o Brasil não tem a opção de viver à margem dos processos globais. Dou um exemplo. Temos um programa de combate à AIDS que é mundialmente reconhecido como resposta a um dos piores dramas vividos pela humanidade em nossos dias. Realizamos, em ampla escala, a distribuição de remédios retrovirais. Mas, para que seja viável em um país com recursos escassos, esse programa depende de que os preços dos medicamentos não ultrapassem certos limites razoáveis. Torna-se essencial, portanto, estabelecer um equilíbrio entre o interesse legítimo das empresas farmacêuticas, que se beneficiam de patentes, e o interesse maior de salvar quantas vidas pudermos. (BRASIL, 2008)

O engajamento do Brasil no combate a doenças de escala global não se limitava à aids. Malária e tuberculose representavam outros desafios, citados abaixo por Celso Amorim. Independente da doença em discussão, o que predominava no discurso brasileiro era a disposição para o diálogo estreito com os países em desenvolvimento.

Em setembro de 2005, em Nova York, na LX Sessão da Assembleia-Geral das Nações Unidas, o ministro Celso Amorim declarou:

Enfrentamos, além dos desafios a que já me referi, duas crises com impacto global: a explosão pandêmica do HIV/AIDS; e as trágicas ameaças derivadas das mudanças climáticas. O Brasil continuará mobilizado para promover a implementação dos instrumentos multilaterais para combater esses flagelos [...] Ajudamos a combater a fome, a desenvolver a agricultura e, com grande empenho, a lutar contra o flagelo do HIV/AIDS em vários países irmãos do continente africano. (BRASIL, 2007)

Na busca de relevância política e participação ativa no cenário internacional, reafirmando o tema da saúde em suas posições oficiais e adaptando suas estruturas político-administrativas, o Brasil de FHC e Lula da Silva demonstrou considerar estratégico formalizar o tema da saúde em sua agenda diplomática, uma vez que isso representava a oportunidade de se tornar uma referência nas discussões globais em saúde e, consequentemente, o fortalecimento de sua presença internacional. 


\section{Conclusões}

Ao demonstrar os compromissos assumidos e as contribuições do Brasil ao debate internacional em saúde, este artigo confirmou as hipóteses de que: 1) o tema da saúde ganhou importância política na agenda da política externa brasileira a partir de 1995 e assim permaneceu até 2010 (marco temporal final desta investigação); e que 2) isso ocorreu em função do objetivo maior da diplomacia brasileira de alcançar posição de influência na política internacional. Os governos de FHC e Lula da Silva, mesmo que formuladores de distintas diretrizes de política externa, garantiram ao tema da saúde um espaço formal na agenda dessa política, entendendo que isso viabilizaria a aspiração de uma participação relevante no cenário internacional, uma vez que Estados, organizações internacionais governamentais e não governamentais de todo o mundo discutiam o tema, oferecendo um espaço amplo de atuação.

De acordo com os dados levantados, o país, nesse espaço, apresentou sua experiência no tratamento do HIV/Aids, contribuiu para a regulação internacional do consumo de tabaco, defendeu o acesso a medicamentos, atuou de modo a fortalecer os processos de formação de pessoal e da infraestrutura de saúde, em apoio aos sistemas de saúde dos países em desenvolvimento, e confirmou os esforços referentes aos Objetivos de Desenvolvimento do Milênio, aumentando sua influência no cenário internacional. Para tanto, mobilizou estruturas políticoadministrativas que possibilitariam participação ativa, constante e consistente no debate internacional, assumiu protagonismo e responsabilidades significativas em diversas ações de cooperação, assim como assumiu, em pronunciamentos oficiais nos fóruns multilaterais, o compromisso com a área da saúde. A presente pesquisa também observou que desenvolvimento, crescimento econômico, comércio, direitos humanos e ética internacional são algumas das áreas com as quais a saúde se relaciona na formulação de política externa desde o fim da Guerra Fria. Essa relação se desenvolve a partir do reconhecimento de que os problemas de saúde afetam, de alguma forma, mesmo que em graus diferentes, as funções centrais da diplomacia, como a busca de desenvolvimento econômico e de influência política, por exemplo.

O presente trabalho reúne e sistematiza informações que se encontram dispersas em documentos oficiais do Ministério da Saúde, do Ministério das Relações Exteriores e de suas respectivas agências. Dados - que nunca foram dispostos em um breve histórico ou relacionados entre si - formaram aqui os contextos 
nacional e internacional em que as áreas de saúde e política externa dialogaram durante os governos de FHC e Lula da Silva, indicando seus atores, interesses e mecanismos institucionais. Dessa forma, o trabalho reforça, para as literaturas dessas áreas, a possibilidade de interação entre elas e indica os níveis políticoadministrativo e de discurso oficial como ferramentas para o estudo dessa interação. Além disso, a pesquisa busca na literatura acadêmica as análises que ajudam a compreensão das iniciativas políticas tomadas por esses governos em saúde e política externa, corroborando a ideia de que esses temas não são exclusivos de grupos implementadores de políticas, mas também da academia, que ainda inicia sua produção nessa área em todo o mundo. Nesse sentido, o futuro da diplomacia em saúde do Brasil representa um tema amplo e importante de pesquisa.

Os resultados desse trabalho indicam como questões para estudo futuro aquelas referentes, principalmente, ao grau de institucionalização alcançado nesse processo, aos resultados efetivos das iniciativas internacionais em saúde do Brasil e à manutenção ou não da saúde como um instrumento para o alcance dos objetivos da política externa do país. São questões que requerem um refinamento das elaborações conceituais, infelizmente ainda escassas ou de pouca profundidade nesse momento; e a união de interesses, recursos de pesquisa e expertise de Relações Internacionais, Saúde Coletiva e demais Ciências da Saúde, Ciência Política e Economia, entre outras áreas, além de esforços de análise tanto da esfera acadêmica quanto da política. Dessa forma, o trabalho não se propõe a responder perguntas clássicas da literatura de política externa sobre os governos de FHC e Lula da Silva ou questões frequentes no debate em saúde, mas incentivar o diálogo entre essas duas áreas e indicar alguns temas pelos quais isso pode acontecer, apontando as dificuldades teóricas para tanto.

\section{Referências}

AGÊNCIA BRASILEIRA DE COOPERAÇÃO. Via ABC, Ministério das Relações Exteriores, 2010. Disponível em: < www.abc.gov.br/intranet/Sistemas_ABC/siteabc/documentos/ viaABC baixa.pdf $>$. Acesso em: 02 jan.2014.

ALCÁZAR, Santiago. A inserção da saúde na política exterior brasileira. Brasília: Instituto Rio Branco, Ministério das Relações Exteriores, Curso de Altos Estudos, p. 1-205, 2005. ALMEIDA, Celia et al. A concepção brasileira de "cooperação Sul-Sul estruturante em saúde”. Revista Eletrônica de Comunicação, Informação e Inovação em Saúde, v. 4, n. 1, p. 25-35, 2010. 
ALVES, J.A.Lindgren. Relações Internacionais e Temas Sociais: a década das conferências. Brasília: IBRI, 2001.

AMORIM, Celso. Discurso do Ministro das Relações Exteriores, Embaixador Celso Amorim, pronunciado, em 28 de outubro de 2003, no México, no debate geral da Conferência Especial de Segurança, no âmbito da OEA. Disponível em: < http://www.itamaraty. gov.br/pt-BR/discursos-artigos-e-entrevistas-categoria/7605-discurso-do-ministrodas-relacoes-exteriores-embaixador-celso-amorim-pronunciado-em-28-de-outubro-de2003-no-mexico-no-debate-geral-da-conferencia-especial-de-seguranca-no-ambitoda-oea > . Acesso em: 22 jan. 2015.

AMORIM, Celso et al. Oslo Ministerial Declaration - Global health: a pressing foreign policy issue of our time. The Lancet, v. 369, n. 9570, p. 1373-1378, 2007.

BRASIL. Extrato do $41^{\circ}$ Termo de Cooperação e Assistência Técnica ao ajuste complementar. Diário Oficial da República Federativa do Brasil, Seção 3, 10 jan. 2006.

BRASIL. Ministério das Relações Exteriores. Balanço da Política Externa 2003 -2010. Brasília, MRE, 2010a.

BRASIL. Ministério da Saúde. Participação do Ministério da Saúde no Cenário Internacional da Saúde: Ciclo de debates: Assessoria Internacional do Ministério da Saúde. Brasília: Ministério da Saúde, 2009a.

BRASIL. Ministério da Saúde. Secretaria-Executiva. Mais Saúde: Direito de Todos 2008-

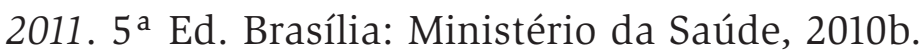

BRASIL. Ministério da Saúde. Ministério das Relações Exteriores. Protocolo de Intenções entre o Ministério das Relações Exteriores e Ministério da Saúde. Brasília: Ministério da Saúde, 2005.

BRASIL. Ministério da Saúde. O Brasil e os ODM, 2014. Disponível em: < http://www. odmbrasil.gov.br/o-brasil-e-os-odm > . Acesso em: 05 março 2014.

BRASIL. Presidente (1995-2003). Discursos selecionados do Presidente Fernando Henrique Cardoso. Brasília: Fundação Alexandre de Gusmão, 2009b. 92p.

BRASIL. Presidente (2003 - :Lula). Discursos selecionados do Presidente Luiz Inácio Lula da Silva. Brasília: Fundação Alexandre de Gusmão, 2008.

BRASIL. O Brasil nas Nações Unidas: 1946-2006: Luiz Felipe de Seixas Corrêa, organizador/ Brasília: Fundação Alexandre de Gusmão, 2007, 768p.

CEPALUNI, Gabriel. Regimes internacionais e o contencioso das patentes para medicamentos: estratégias para países em desenvolvimento. Contexto Internacional, v. 27, n. 1. Rio de Janeiro, 2005. Disponível em: < http://www.scielo.br/scielo.php?pid= S0102-85292005000100002\&script = sci_abstract\&tlng = pt > . Acesso em: 12 abril 2014 . CERVO, Amado. A política exterior: de Cardoso a Lula. Revista Brasileira de Política Internacional, v. 46, n. 1, 2003. Disponível em: < http://www.scielo.br/scielo.php? script = sci_arttext\&pid = S0034-73292003000100001 > . Acesso em: 02 fev. 2014 . 
CERVO, Amado; BUENO, Clodoaldo. História da Política Exterior do Brasil. Brasília: Editora UnB, 2011.

FIDLER, David. Health in foreign policy: An analytical overview. Canadian Foreign Policy Journal, v.15, n.3, 2009. Disponível em: < http://graduateinstitute.ch/files/live/sites/ iheid/files/sites/globalhealth/shared/Training/SEEHN_course/fidler \%20health \% 20 in \%20foreign \% 20policy \% 202011.pdf > . Acesso em: 01 dez. 2013.

LIMA, Maria Regina. Aspiração Internacional e Política Externa. Revista Brasileira de Comércio Exterior, n.82, ano XIX, 2005.Disponível em: < file://C:/Users/tmarques/ Downloads/LIMA_aspira \% C3\% A7 \% C3 \% A3o_internacional_pol\%C3\% ADtica_ externa.pdf > . Acesso em: 02 nov. 2013.

PAROLA, Alexandre. A ordem injusta. Brasília: FUNAG, 2007.

PECEQUILO, Cristina. A política externa do Brasil no século XXI: os eixos combinados de cooperação horizontal e vertical. Revista Brasileira de Política Internacional, v. 51, n. 2, 2008. Disponível em: < http://www.scielo.br/scielo.php?pid=S0034$73292008000200009 \&$ script $=$ sci_abstract\&tlng $=$ pt $>$. Acesso em: 20 jan. 2014.

PINHEIRO, Letícia. Política Externa Brasileira (1889-2002). Rio de Janeiro: Jorge Zahar Editora, 2004.

PIRES-ALVES, Fernando; PAIVA, Carlos; SANTANA, José. A internacionalização da saúde: elementos contextuais e marcos institucionais da cooperação brasileira. Rev. Panam Salud Publica, v. 32, n. 6, p. 444-50, 2012. Disponível em: < http://pesquisa.bvs. br/brasil/resource/pt/lil-662924 > . Acesso em: 03 fev. 2014.

PONTE, Carlos. Pesquisa versus Produção em Manguinhos: constrangimentos e perspectivas de desenvolvimento tecnológico em uma instituição pública. 2012. Tese (Doutorado em Políticas Públicas, Estratégias e Desenvolvimento) - Universidade Federal do Rio de Janeiro, Rio de Janeiro.

PUNTIGLIANO, Andrés. Tornando-se Global: Um estudo organizacional da política externa brasileira. Revista Brasileira de Política Internacional, v.51, n.1, p. 28-52, 2008. Disponível em: < http://www.scielo.br/scielo.php?pid = S0034-73292008000100002\&script = sci_ abstract\&tlng $=$ pt $>$. Acesso em: 03 jan. 2014.

RUBARTH, Ernesto. A Diplomacia Brasileira e os Temas Sociais: o caso da Saúde. Brasília: Instituto Rio Branco, Fundação Alexandre Gusmão, Centro de Estudos Estratégicos, 1999.

SARAIVA, Miriam. As estratégias de cooperação Sul-Sul nos marcos da política externa brasileira de 1993 a 2007. Revista Brasileira de Política Internacional, v. 50, n. 2, 2007. Disponível em: < http://www.scielo.br/scielo.php?pid = S0034-73292007000200004\& script $=$ sci_abstract\&tlng $=$ pt $>$. Acesso em: 01 março 2014 .

SÁ-SILVA, Jackson; ALMEIDA, Cristóvão; GUINDANI, Joel. Pesquisa documental: pistas teóricas e metodológicas. Revista Brasileira de História e Ciências Sociais, n. 1, p. 1-14, 2009. Disponível em: < https://www.rbhcs.com/rbhcs/article/view/6 > . Acesso em: 02 jan. 2014. 
SOUZA, Amaury. Agenda Internacional do Brasil: um Estudo sobre a Comunidade Brasileira de Política Externa. Rio de Janeiro: CEBRI, 2002.

SOUZA, André. Saúde pública, patentes e atores não estatais: a política externa do Brasil ante a epidemia de AIDS. In: Letícia Pinheiro e Carlos Milani (Org.), Política Externa Brasileira: A política das práticas e as práticas da política. Rio de Janeiro: FGV, 2011. TOSCANO, Marcela. A Formação do Regime Internacional de Controle do Tabaco: 1999 a 2005. 2006. Dissertação (Mestrado em Relações Internacionais) — Universidade de Brasília, Brasília.

VAZ, Alcides Costa. Brazilian foreign policy under Lula: Change or continuity? Friedrich Ebert Foundation. Briefing Paper, 2004.

VIGEVANI, Tullo; CEPALUNI, Gabriel. A Política Externa de Lula da Silva: a Estratégia da Autonomia pela Diversificação. Contexto Internacional, v. 29, n. 2, 2007. Disponível em: < http://www.scielo.br/scielo.php?script = sci_arttext\&pid = S0102-85292007000200002 > . Acesso em: 05 set. 2013.

VIGEVANI, Tullo; OLIVEIRA, Marcelo. A política externa brasileira na era FHC: um exercício de autonomia pela integração. Tempo Social, v. 15, n. 2, 2003. Disponível em: < https://periodicos.ufsc.br/index.php/interthesis/article/view/708 > . Acesso em: 05 nov. 2013. 